

(C) 2018 American Meteorological Society. For information regarding reuse of this content and general copyright information, consult the AMS Copyright Policy (www.ametsoc.org/PUBSReuseLicenses).

\title{
Using "Locall Climate Zones" to Detect Urban Heat Island on Two Small Cities in Alabama
}

\section{Jeff Chieppa ${ }^{\mathrm{a}}$}

Hawkesbury Institute for the Environment, Western Sydney University, Richmond, New South Wales, Australia

\section{Austin Bush and Chandana Mitra}

Department of Geosciences, College of Sciences and Mathematics, Auburn University, Auburn, Alabama

Received 25 August 2017; in final form 3 April 2018

\begin{abstract}
Classifying "urban" and "rural" environments is a challenge in understanding urban climate, specifically urban heat islands (UHIs). Stewart and Oke developed the "local climate zone" (LCZ) classification system to clarify these distinctions using 17 unique groups. This system has been applied to many areas around the world, but few studies have attempted to utilize them to detect UHI effects in smaller cities. Our aim was to use the LCZ classification system 1) to detect UHI in two small cities in Alabama and 2) to determine whether similar zones experienced similar intensity or magnitude of UHIs. For 1 week, we monitored hourly temperature in two cities, in four zones: compact
\end{abstract}

O) Supplemental information related to this paper is available at the Journals Online website: https://doi.org/10.1175/EI-D-17-0020.s1.

\footnotetext{
${ }^{a}$ Corresponding author: Jeff Chieppa, jjchieppa@gmail.com
} 
Earth Interactions - Volume 22 (2018) - Paper No. 16 • Page 2

low-rise, open low-rise, dense forests, and water. We found that urban zones were often warmer for overall, daytime, and nighttime temperatures relative to rural zones (from $-0.1^{\circ}$ to $2.8^{\circ} \mathrm{C}$ ). In addition, we found that temperatures between cities in similar zones were not very similar, indicating that the LCZ system does not predict UHI intensity equally in places with similar background climates. We found that the LCZ classification system was easy to use, and we recognize its potential as a tool for urban ecologists and urban planners.

KEYWORDS: Land surface; Temperature; Geographic information systems (GIS); In situ observations; Land use; Urban meteorology

\section{Introduction}

Urban heat island (UHI) refers to the enhanced atmospheric warmth of a city relative to its countryside: the urban-rural difference in temperature (Balchin and Pye 1947; Stewart and Oke 2012; Ng 2015). Land-use changes are one of the driving factors creating UHIs in urban areas. More specifically, converting changing land from vegetation to urban structures (buildings and roads) alters the natural surface energy and radiation balances (Oke 1982; Lowry and Lowry 2001). Increasing land cover with anthropogenic materials such as asphalt/concrete can result in greater heat storage capacity (Grimmond 2007). Ultimately, surface characteristics determine the net amount of radiation, which drives the energy flux at the surface (Li Bou-Zeid and Oppenheimer 2014). The energy partitioning or, more precisely, the sensible heat flux influences the ambient temperature. Changes in land use and land cover (decreasing albedo and increasing impervious areas) can have implications related to temperature, precipitation, and hydrology that have direct and indirect effects on both humans and their surrounding environments (McDonnell et al. 1993, 1997; Mitra et al. 2012). For example, Dou et al. (2015) found that the intensity of UHI had contrasting effects on inner-city precipitation, with strong UHIs enhancing thunderstorm formation and weak UHIs decreasing rainfall. In the latter case, the bifurcated form resulted in above-normal precipitation in areas outside the urban zone. Theoretically, more individuals will face the changes in temperature imposed by heat variability as the population is increasingly living in urban and urban-adjacent zones (Cohen 2006; Heilig 2012).

Within the urban climate literature on UHIs, there is often an issue in defining the terms "urban" and "rural." Stewart (2011) reviewed the relevant research and concluded that a major flaw in the existing literature is the lack of important site metadata regarding field site characteristics. To address the challenge of relating UHI presence to land-cover type, Stewart and Oke (2012) developed the "local climate zone" (LCZ) classification system. The classification system incorporates three categories: built series, land-cover series, and variable land-cover properties (Table 1). There are 10 built types that define a range of building arrangements. For example, LCZ 1 compact high-rise would be major metropolitan areas with densely formed high-rise buildings (e.g., Manhattan in New York City, New York). Land-cover series comprise seven types (named from A to G). These describe the more natural aspects of land cover (dense forest, sand, water, etc.). Together, these provide a largely nonvariable environmental assessment of land cover, or those that do not change during season and irregular climatic events (e.g., flooding associated with a hurricane) (Stewart and Oke 2012). The third category, variable land-cover 
Earth Interactions • Volume 22 (2018) • Paper No. 16 • Page 3

Table 1. Categories and characteristics of LCZs from Stewart and Oke (2012).

\begin{tabular}{llc}
\hline \multicolumn{1}{c}{ Built types } & \multicolumn{1}{c}{ Land-cover types } & Variable land-cover properties \\
\hline LCZ 1: Compact high-rise & LCZ A: Dense trees & b: Bare trees \\
LCZ 2: Compact midrise & LCZ B: Scattered trees & s: Snowy cover \\
LCZ 3: Compact low-rise & LCZ C: Bush, scrub & d: Dry ground \\
LCZ 4: Open high-rise & LCZ D: Low plants & w: Wet ground \\
LCZ 5: Open midrise & LCZ E: Bare rock/paved & \\
LCZ 6: Open low-rise & LCZ F: Bare soil/sand & \\
LCZ 7: Lightweight low-rise & LCZ G: Water & \\
LCZ 8: Large low-rise & & \\
LCZ 9: Sparsely built & & \\
LCZ 10: Heavy industry & & \\
\hline
\end{tabular}

properties, includes four types that include bare trees (i.e., deciduous, leafless forests), snow cover, dry ground, and wet ground. These variable descriptions allow for seasonal comparisons or following extreme climatic events (flooding or drought). Overall, each LCZ is indicative of surface property values, including aspect ratio, sky view factor, and impervious surface fraction [see Stewart and Oke (2012) for descriptions].

Many studies have been conducted on UHI; however, the majority of studies have focused on large urban areas such as New York City (Bornstein 1968); Atlanta, Georgia (Bornstein and Lin 2000); Singapore (Chow and Roth 2006); and Mexico City, Mexico (Cui and de Foy 2012). These examples provide useful information of comparing well-defined urban and rural areas. Less work has been done utilizing urban-rural gradients (Imhoff et al. 2010), which might be more important for characterizing the locations of UHIs in urban-adjacent areas (e.g., suburbs, subdivisions and city sprawl). Before the LCZs were defined, this was a difficult task. Since publication in 2012, the LCZ system has been used to detect and quantify UHI intensity in Singapore (Ng 2015); Nagano, Japan; Vancouver, British Columbia, Canada; Uppsala, Sweden (Stewart et al. 2014); Novi Sad, Serbia (Savić et al. 2013); and Phoenix, Arizona (Middel et al. 2014) and in general across the United States (Zhao et al. 2014). While useful, no study to our knowledge has utilized smaller cities $(<100000$ people). Research has been conducted in the Auburn-Opelika (Alabama) area to determine the UHI presence without LCZs, which showed that from the period of 1 March to 31 August 2014 there was an average UHI intensity of $4.39^{\circ} \mathrm{F}\left(2.44^{\circ} \mathrm{C}\right)$ (Hug 2014). In addition, no study has compared UHI in multiple locations to determine whether the UHI can be predicted using LCZs in comparable cities.

While LCZs have been used within several cities, the main challenges of comparing cities are their size, background climate, and anthropogenic activities (e.g., traffic patterns). For example, $\mathrm{Ng}$ (2015) detected a $2.01^{\circ} \mathrm{C}$ UHI in Singapore using sparsely built (LCZ 9) as the rural setting and open high-rise as the urban setting. Alexander and Mills (2014) derived an overnight UHI of $4.8^{\circ} \mathrm{C}$ between low plants (LCZ D) and compact midrise (LCZ 2). Leconte et al. (2015) found a much lower UHI of $0.8^{\circ} \mathrm{C}$, relative to that of Alexander and Mills (2014), using the same LCZs; however, the cities studied differed in background climate, which is an important factor contributing to UHI (Zhao et al. 2014). Smaller cities, in addition, may be subject to greater growth rates than are larger cities (Rahman 2014). 


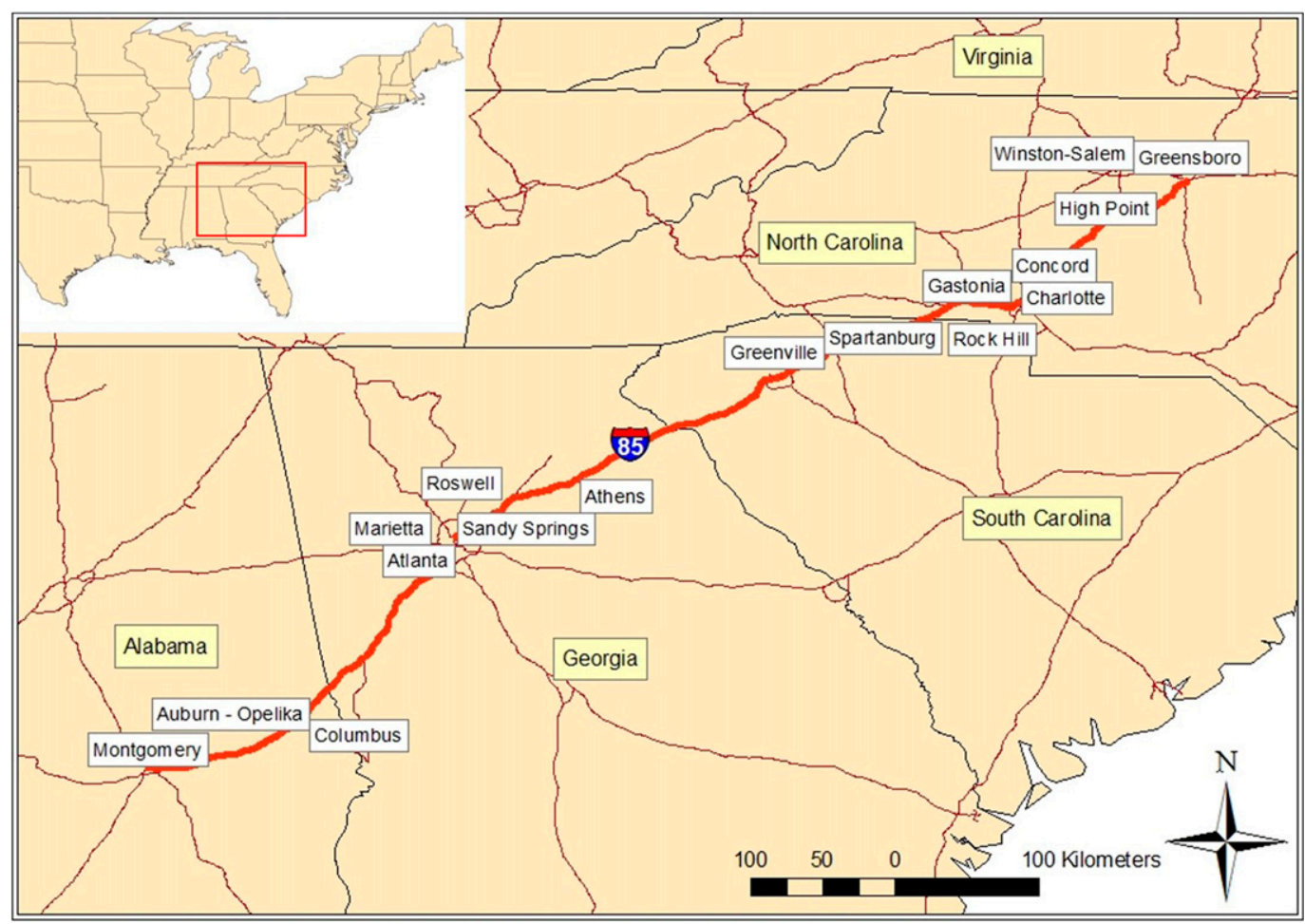

Figure 1. The I-85 corridor, including cities contributing to the urbanization of the region (see supplemental Table S1 for population information).

Therefore, more information on the relationship between temperature and urbanization in smaller cities will assist in developing adaptation and mitigation techniques (Stone et al. 2010).

The southeastern United States provides an ideal opportunity to utilize the LCZ system for the assessment of smaller cities $(<100000$ people). Wear and Greis (2002) predicted that the Southern Piedmont (Figure 1) will be among the areas of greatest urbanization. This area, referred to as the "I-85 corridor" because of the presence of that interstate highway, has undergone massive population growth over the last 20-30 years (see Table S1 of the online supplemental material). Others have already started utilizing this area to study urban-rural ecology (Lockaby et al. 2005; Nagy and Lockaby 2011). From 2004 to 2005, there were over 10000 instances of heat-related illness reported in the United States, with $60 \%$ of them occurring in the southern region (Noe et al. 2012). In addition, most heat-related illness issues occur in rural counties, which could be exacerbated by rapid change in land use, particularly in the southern United States (Bernhard et al. 2015). Other studies investigating heat-related illness/death as a result of urban environments estimated 3500-27000 heat-related deaths by the mid-twenty-first century in the United States (Voorhees et al. 2011). Others investigating individual cities expect mortality to increase by a factor of 2-7 (Hayhoe et al. 2004; Peng et al. 2011; Sheridan et al. 2012). Developing (urbanizing) regions will likely increase as a 
Earth Interactions - Volume 22 (2018) • Paper No. 16 • Page 5

result of urban sprawl and become subjected to urban health issues resulting from changes in the physical environment (McMichael 2000; Frumkin 2002; Stone et al. 2010).

This study, which focuses on the small to midsized cities of Auburn and Opelika (site descriptions below), aims to contribute to limited literature on smaller urban areas, which are growing and often differ in urban topography and LCZs. For this project, we had two objectives. First, we wanted to detect UHI in multiple areas (with varying urbanization levels) using the LCZ classification system. We hypothesized that the LCZ classification system could be used to detect UHI and that urban intensity would increase overall temperature during the daytime and at nighttime. Second, we wanted to determine if the intensity of the UHI effect was similar across the same LCZs between similarly developed cities with comparable background climates.

\section{Materials and methods}

\subsection{Site descriptions and climate}

Auburn and Opelika are in Lee County, which is in the central-eastern portion of the state. Along with Phenix City and a few other small towns, the Auburn-Opelika Metropolitan Statistical Area is one of the fastest-growing populations in the region (U.S. Census; https://www.census.gov/). Auburn has a population of 62059 (2015 estimate), and Opelika has a population of 29527 (2015 estimate). From 1980 to 2010 , the city of Auburn's population increased by approximately $87.5 \%$, from 28471 in 1980 to 53380 in 2010 (Rahman 2014). Total urban built-up area net addition was $600 \%$ (from 5.4\% to 33.7\%) between 1982 and 2010 (Rahman 2014). Auburn University is housed within the city of Auburn, with an enrollment of 25078 students in 2010 (students are not included in municipal population unless they are permanent residents). The area is representative of typical urban sprawl, with an epicenter of urbanized area from community establishment and budding suburbs/shopping areas moving into the extensive pine plantations of the region.

Auburn and Opelika are directly adjacent and share nearly all climatic characteristics. Both cities are considered to be subtropical. Mean annual precipitation is $\sim 1340 \mathrm{~mm}$. Average high temperature for the year is $23.9^{\circ} \mathrm{C}$, and the corresponding low is $11.7^{\circ} \mathrm{C}$. In June (when this study was conducted), the average high and low are $31.3^{\circ}$ and $19.4^{\circ} \mathrm{C}$, respectively. June precipitation is typically $117.1 \mathrm{~mm}$ occurring over 10.1 days (National Oceanic and Atmospheric Administration station AL AUBURN AGRONOMY FARM; accessed 16 May 2017).

\subsection{LCZ classifications}

When creating a local-climate-zone classification, it is important to consider the fact that there are multiple proven methods to use, including manual sampling of grid cells using Geo-Wiki, digitizing homogenously developed LCZs, and a GIS method that uses building data, supervised pixel classification, and object-based image analysis (Betchel et al. 2015). For this study, we opted for the GIS-based approach, focusing on using a pixel-based classification method using a template 
Earth Interactions - Volume 22 (2018) • Paper No. 16 • Page 6

LCZ (".kml") that is provided by the researchers associated with the World Urban Database and Access Portal Tools (WUDAPT) project (http://wudapt.org). The WUDAPT is an initiative to collect data on the form and function of cities globally by using the LCZ classification framework to provide better urban climate classification. As part of this initiative, there is the desire to make the methodology used in LCZ creation a uniform and user-friendly process, which is why the GIS approach is promoted as an ideal method by WUDAPT. After obtaining the startup files from WUDAPT, Google Earth is then used to perform the training-site classifications. These training sites are polygonal boundaries drawn over select land uses that correspond to their LCZ categories. Within each of these polygons are sample pixels that will be used in the supervised classification. Training sites are needed for the automated classification process to be able to designate which type of land cover corresponds to which classification.

After creating these training sites, the files are then imported into open-source GIS software, the System for Automated Geoscientific Analyses (SAGA). SAGA acts as the platform in which the classifications will be created. Along with importing the vector training site files into SAGA, Landsat-8 satellite images are used for the region of interest, ours being Auburn-Opelika. A Landsat-8 tile with minimal cloud coverage that was taken during the month of June 2015 was selected for use. These Landsat-8 images are then imported into SAGA and merged with the vector training-sites file. After merging the files and making sure they share the same projection, the Landsat image is then clipped to the region of interest's size. By using the Random Forest (ViGrA) function in SAGA, we were then able to perform the classification. After the classification was performed, the results needed to be refined to create a substantial end-product classification. The GIS approach used in this study is an iterative process that allows the user to observe their results and redo the training sites to get their desired accuracy. This method is heavily dependent on the quality of the researcher's training sites used for the classification, so oftentimes this will be the step in the process that is repeated several times for improved accuracy.

The analyses resulted in four LCZs that could be replicated twice in each city. Overall, we found there to be LCZ 3 [compact low-rise (CLR)], LCZ A (dense forest, herein forest), LCZ 6 [open low-rise (OLR)], and LCZ G (water) (Figures 2 and 3). These four LCZ classes represent most of the land-use/land-cover composition in the Auburn-Opelika region, so they were deemed to be the LCZs of interest for this study; other less significant LCZ classes were not assessed because of their very minor presence in the region (Figures 4 and 5). An overall assessment of the LCZs in the Auburn-Opelika area is presented in Figure 6.

\subsection{Site selection}

Potential sites were selected on the basis of the results of the LCZ analyses. Site distances between LCZs were, at a minimum, $500 \mathrm{~m}$ to ensure minimal blending or "spillover" in temperatures, as suggested by Stewart and Oke (2012), with the exception of one forest and one water site for which the distance was $112 \mathrm{~m}$. Initial site visits were conducted to ensure similar visual characteristics within LCZs and to avoid sites with potential issues such as slope, alleyways, excessive shading, and 
Earth Interactions - Volume 22 (2018) - Paper No. 16 • Page 7
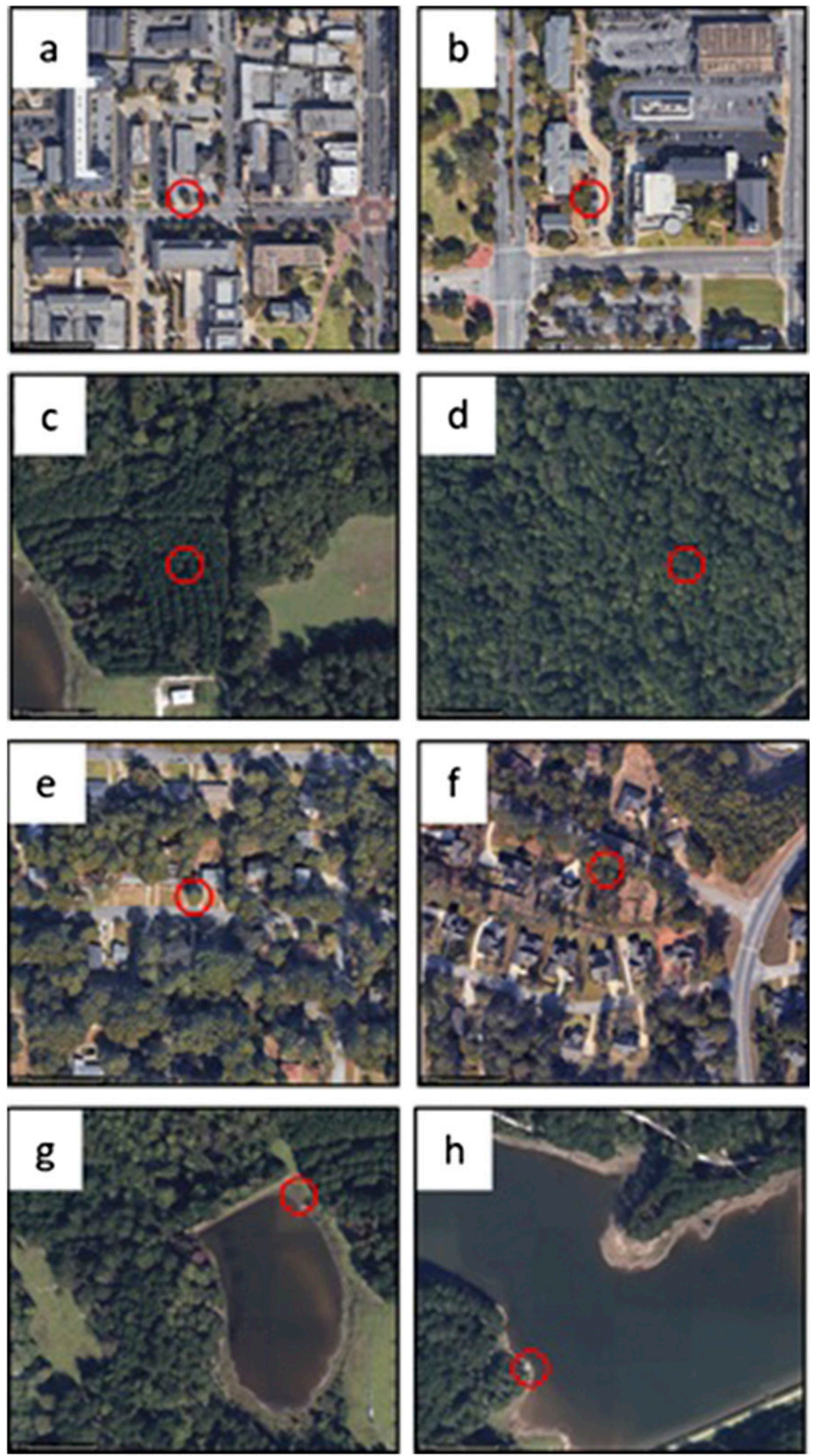

Figure 2. Aerial images for selected sites in Auburn, including (a) Aul (CLR), (b) Au2 (CLR), (c) Au3 (forest), (d) Au4 (forest), (e) Au5 (OLR), (f) Au6 (OLR), (g) Au7 (water), and (h) Au8 (water). Circles indicate datalogger location (diameter is $\sim 40 \mathrm{~m}$ ). 
Earth Interactions - Volume 22 (2018) • Paper No. 16 • Page 8
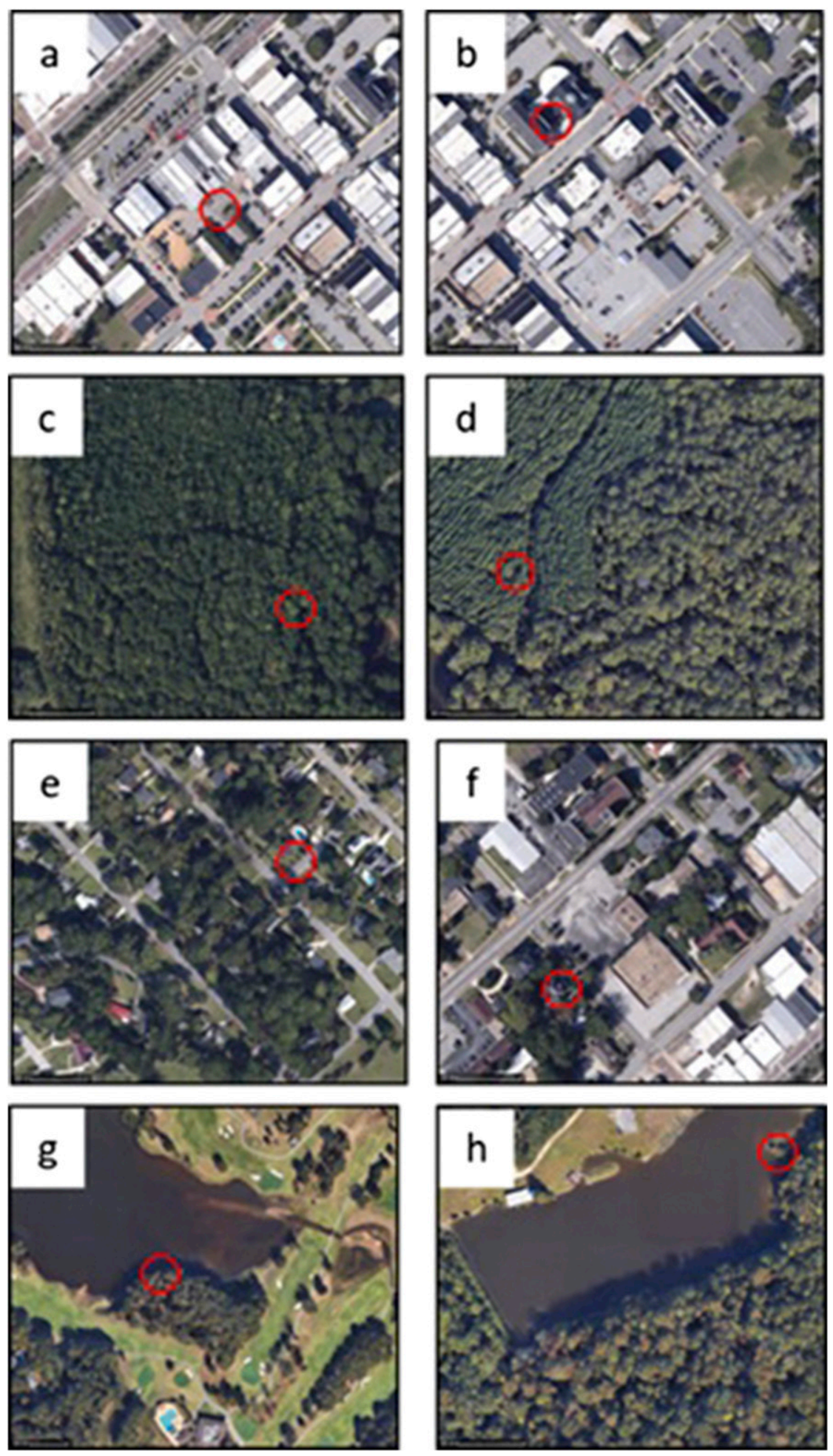

Figure 3. As in Figure 2, but for sites Op1-Op8 in Opelika. The LCZs associated with the sites are the same as in Figure 2. 


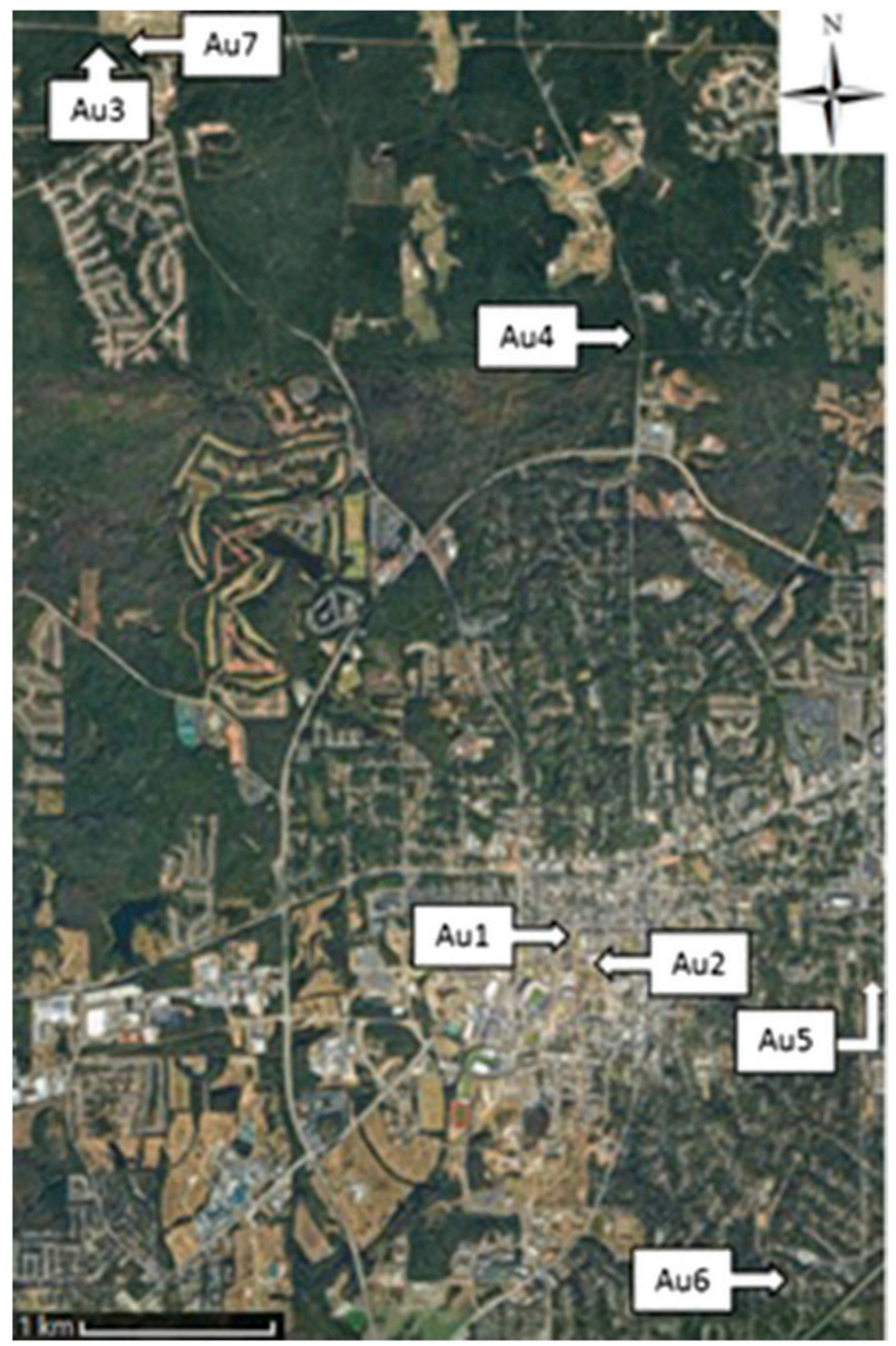

Figure 4. Site selections for Auburn. The labels correspond to site names in Figure 2.

depression that could affect temperature (Stewart et al. 2014). Landowners were contacted during initial visits to gain permission to deploy dataloggers.

Site-specific data collection with regard to urban form has been discussed by Mills et al. (2015). In essence, there are three levels at which data about sites are provided (levels 0,1 , and 2). Level 0 uses WUDAPT to provide a basic description 


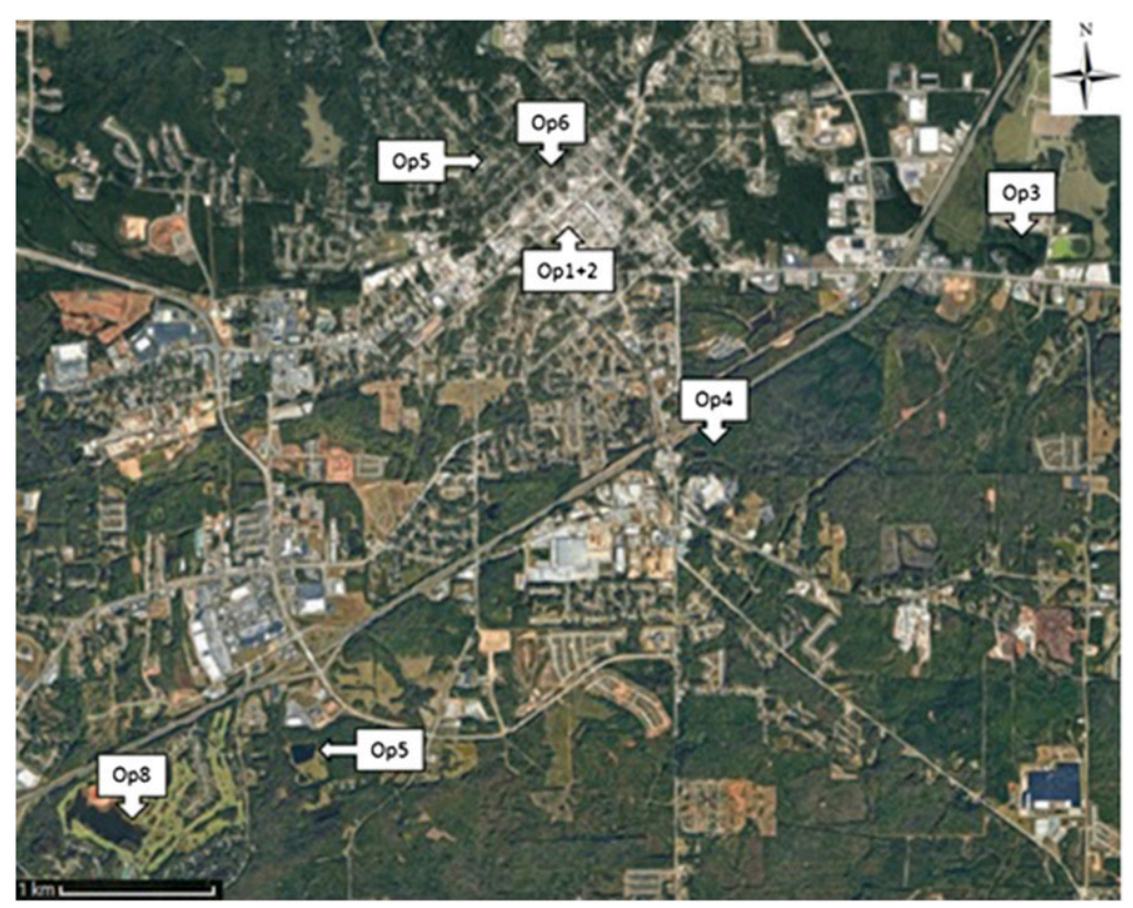

Figure 5. Site selections for Opelika. The labels correspond to site names in Figure 3.

of the urban area and is linked to a range of parameters [see Stewart and Oke (2012), their Table 3]. Levels 1 and 2 provide further detail that may be useful for detailed modeling approaches, because they integrate the in-depth distinction of form, function, and data that is required for boundary layer models (Mills et al. 2015). While unable to provide detail for all sites (e.g., forests with no Google Street View available), we have provided parameters for each site when possible. Google Maps (satellite images) and Street View were used for providing these data (supplemental Table S2).

\subsection{Dataloggers}

In Auburn, eight Onset Computer Corporation "HOBO" Temperature/Relative Humidity/2x External Channel Data Loggers (model H08-007-02) were used. In Opelika, eight HOBO Temperature Data Loggers (model H08-001-02) were used. Each datalogger was placed in a small wooden box $(25 \mathrm{~cm} \times 25 \mathrm{~cm} \times 25 \mathrm{~cm})$ to minimize exposure to rainfall and direct sunlight, and 15-25 holes (each $12.7 \mathrm{~mm}$ in diameter) were drilled to allow airflow. Boxes were painted white to increase albedo, mimicking the design of the commonly used Stevenson screen (Sparks 1972; Huband et al. 1984). Each box was tied to a tree $1.5 \mathrm{~m}$ above the ground (below tree canopy) at each site (coordinates are given in supplemental Table S3).

Dataloggers were programmed to collect temperature every hour, starting at 0000 LT 18 June until 2300 LT 24 June 2015. At the conclusion of sampling, data 


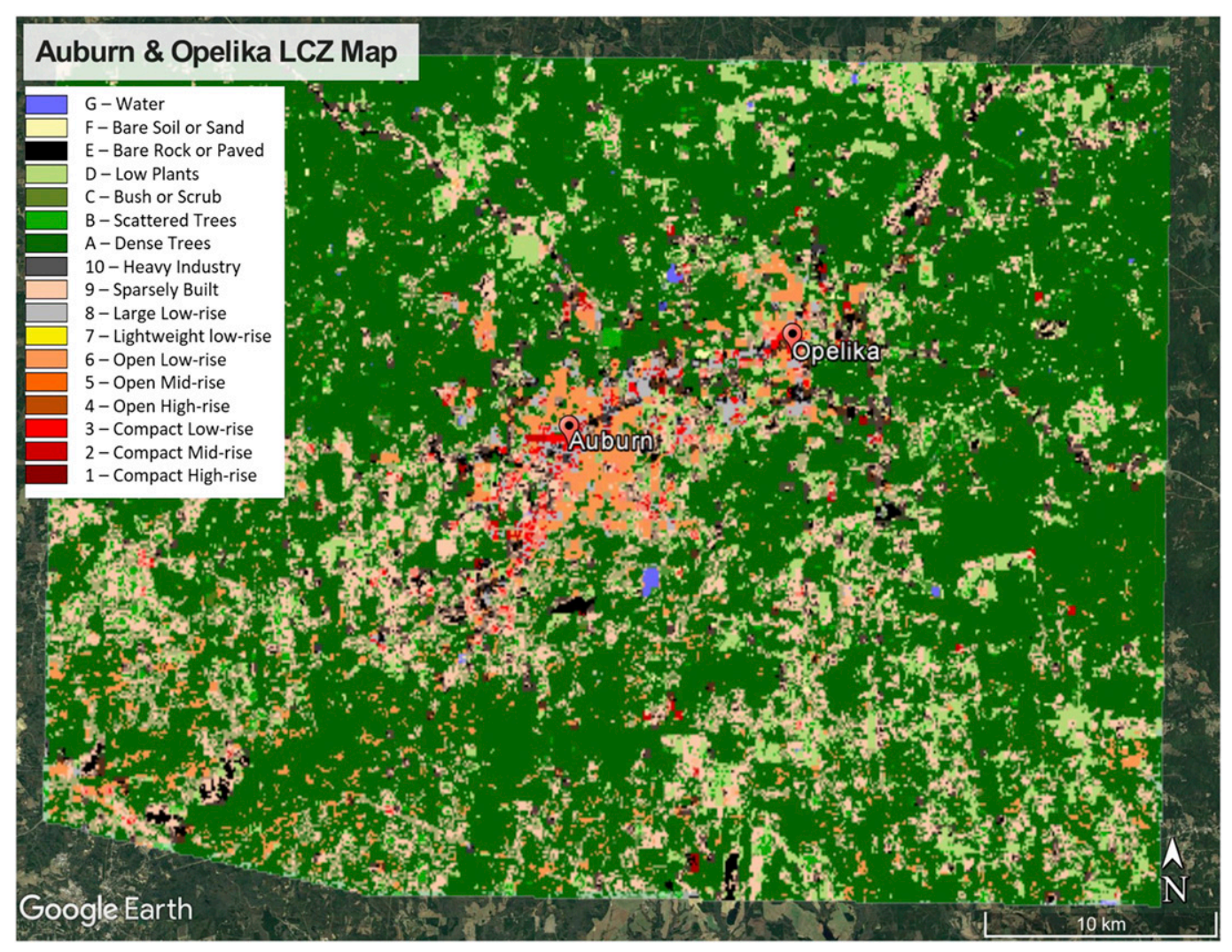

Figure 6. LCZ classification map for Auburn and Opelika.

were extracted using the Onset Computer Corp. BoxCar Pro 4.3 product. The temperature data were checked for quality using nearby weather stations to determine whether the dataloggers were reading accurately. A preliminary 48-h test was conducted (at a single site) to determine temperature variability among the loggers. Maximum and minimum percent differences from the mean temperature were $-1.824 \%$ and $1.826 \%$, respectively. Dates for the experiment were selected to coincide with the forecast calling for slightly above-average temperatures and low wind speeds, which would be ideal to detect temperature anomalies. The nearest weather station to all sites was the Auburn-Opelika Airport weather station $\left(32^{\circ} 37^{\prime} 05.1^{\prime \prime} \mathrm{N}, 85^{\circ} 26^{\prime} 06.2^{\prime \prime} \mathrm{W}\right)$, from which we obtained a comparable base set of temperature measurements and wind speed/direction (https://www. wunderground.com).

\subsection{Data analysis}

The experimental design consisted of four LCZs, each replicated twice per city for a total of 16 sites. One site (Au8) failed to collect data, and therefore the site total for analysis included 15 sites. All statistical analyses were conducted using 
Earth Interactions - Volume 22 (2018) - Paper No. 16 • Page 12

the R software package (http://www.r-project.org). Analysis of variance (ANOVA) $F$-test procedures were followed by post hoc Tukey (honest significant difference) procedures using both Kolmogorov-Smirnov and Lilliefors tests (Morris et al. 2001; Chang et al. 2007; Oliveira et al. 2011). Homogeneity of variance was inspected visually in addition to using both Leven's and Bartlett's tests (Box 1953; Markowski and Markowski 1990). The treatment used for analysis was the sites themselves; however, the post hoc analysis would be used to address the appropriate hypothesis. Alpha was set at 0.05 . Data were divided into subsets for three specific analyses to determine whether UHI was detected for 1) all data, 2) daytime, and 3) nighttime. Daytime data are for temperatures recorded between sunrise (0530 LT) and sunset (1950 LT). Nighttime data are for the opposite times of daytime data.

UHI was calculated using the formula $\mathrm{UHI}=T_{\text {urban }}-T_{\text {rural }}$, where $T_{\text {urban }}$ is the temperature in the urban area and $T_{\text {rural }}$ is the temperature in an adjacent rural area (Zhao et al. 2014). Temperature values (means) used to calculate UHI intensity were derived by using daily and weekly data. In addition, daytime (after 0530 and before $1950 \mathrm{LT}$, based on local sunrise/sunset times) and nighttime temperatures (after 1950 and before 0530 LT) were considered. Calculations were used within each city, and we considered the forests as rural and either compact low-rise or open low-rise as urban. Two of each LCZ type were sampled per city, and the data were averaged for calculations. In addition, daily data were averaged, and wholeweek temperature anomaly was calculated.

\section{Results}

\subsection{Locall weather report}

Daily mean temperature observations from the Auburn-Opelika Airport (11-17 June 2015) were $24^{\circ}, 24^{\circ}, 24^{\circ}, 25^{\circ}, 27^{\circ}, 27^{\circ}$, and $28^{\circ} \mathrm{C}$. Daily maximum temperatures were $29^{\circ}, 29^{\circ}, 30^{\circ}, 31^{\circ}, 33^{\circ}, 32^{\circ}$, and $33^{\circ} \mathrm{C}$, and the daily minima were $19^{\circ}$, $19^{\circ}, 18^{\circ}, 19^{\circ}, 21^{\circ}, 22^{\circ}$, and $22^{\circ} \mathrm{C}$. Mean wind speeds $\left(\mathrm{km} \mathrm{h}^{-1}\right) /$ directions for each day were 11/S, 11/SSW, 6/SSE, 5/SE, 4/S, 8/WNW, and 7/WSW. Maximum daily speeds were $24,19,24,13,14,14$, and $13 \mathrm{~km} \mathrm{~h}^{-1}$.

\subsection{Summary statistics and $F$ tests}

A summary of daily mean, maximum, and minimum temperature is provided in online supplementary Table S4. Analyses resulted in overall significant differences for overall temperature data $(F=14.635 ; p<0.0001)$, daytime temperature $(F=$ $11.322 ; p<0.0001)$, and nighttime temperature $(F=11.171 ; p<0.0001)$. Post hoc analysis for all data indicates that CLR sites had the greatest overall temperatures (Figure 7). Forests tended to have the lowest temperature; however, they were not always significantly different from other LCZs, including CLR sites. Similarly, daytime temperatures were greatest at CLR sites. Forests were coolest. Water and OLR were similar to each other although highly variable across sites during the day (Figure 8). 


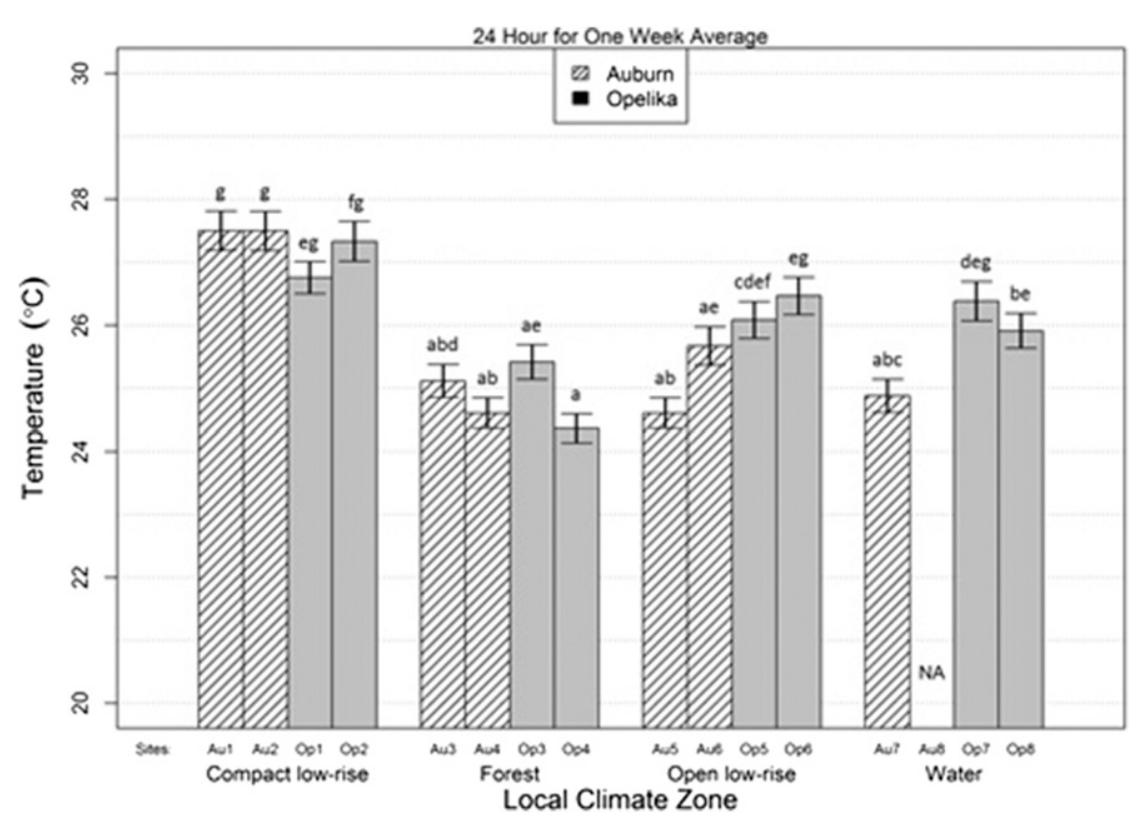

Figure 7. Average temperature (recorded hourly) for 1 week, including the standard error. Letters represent Tukey pairwise comparisons (letters that are not shared represent significant differences at $95 \%$ confidence). The label NA indicates that data are not available because the datalogger failed.

During nighttime hours, temperatures were greatest at CLR sites. Forests tended to be the coolest; however, they were found to be similar to OLR sites (Figure 9). Water sites were intermediate, in that temperatures tended to be cooler $\left(21.8^{\circ} \pm\right.$ $0.3^{\circ} \mathrm{C}$ ) than at CLR sites but comparable to those at the remaining two LCZs. Overall, only during nighttime hours were temperatures all significantly greater for CLR sites relative to all forest sites.

\subsection{UHI intensity}

In Opelika, the weekly overall UHI intensity was $2.2^{\circ}$ and $1.4^{\circ} \mathrm{C}$ for CLR and OLR sites, respectively (Table 2). In Auburn, the weekly overall UHI intensity was $2.6^{\circ}$ and $0.3^{\circ} \mathrm{C}$ for CLR and OLR sites, respectively (Table 3). In both Auburn and Opelika, UHI intensities were larger for daytime temperatures relative to both overall and nighttime UHI intensities. In Auburn, nighttime UHI intensity for OLR sites was less than or equal to zero on 6 of the 7 days (range from $-0.3^{\circ}$ to $0.2^{\circ} \mathrm{C}$ ), with a mean of $-0.1^{\circ} \mathrm{C}$ for the whole week. For both Auburn and Opelika, all UHI intensities (daytime, nighttime, and overall) were greater at CLR sites than at OLR sites. Intensities of UHI at CLR sites for Auburn and Opelika were similar, and daily calculations followed similar trends, with Auburn UHI intensity being slightly greater. When OLR sites were compared between cities, Opelika had a distinctly greater UHI intensity for OLR sites (daytime maximum $=1.5^{\circ} \mathrm{C}$ ), whereas Auburn OLR sites had a maximum UHI intensity of $0.9^{\circ} \mathrm{C}$ on the fourth day of the experiment. 


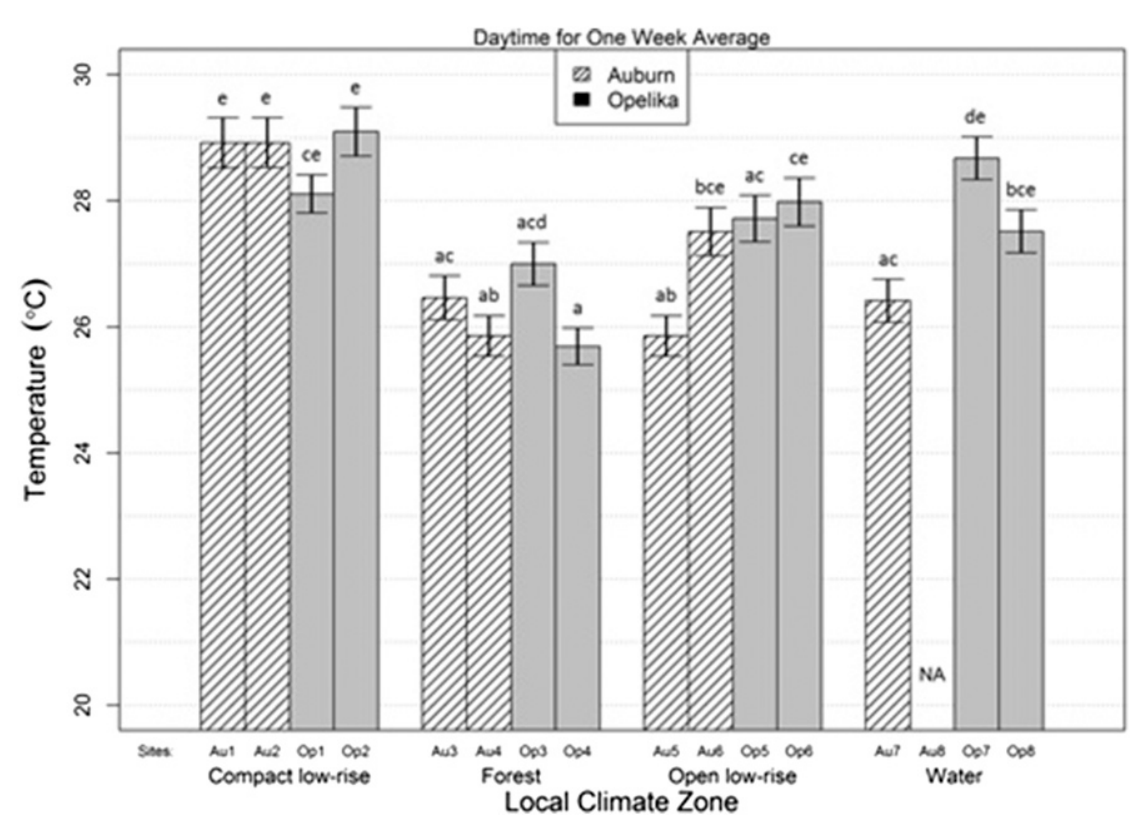

Figure 8. As in Figure 7, but during daytime hours (0500-1900 LT).

\section{Discussion}

\subsection{Classifying LCZs in small cities}

A challenging aspect in UHI intensity studies for a long time has been how to classify urban and rural. The development of LCZs has been a useful tool in classifying these land-cover types in addition to transitional areas. We found utilizing LCZs in the small cities of Auburn and Opelika to be more challenging than expected. We were able to find several LCZs in each area, but we found that they are not expansive. Therefore, utilizing any predictions that are based on our analyses would be difficult. The "patchiness" of the LCZs in small cities is a challenge that could be addressed by utilizing a high number of areas, with each area being smaller. For example, a $10 \mathrm{~km} \times 10 \mathrm{~km}$ area gridded by $2 \mathrm{~km}$ would be less useful than gridding by $0.5-\mathrm{km}$ sections. This would enhance the use in small cities but would require much more analysis than in larger cities.

In addition, when looking at the surrounding land use/land cover of each LCZ site within Auburn and Opelika, there are notable differences that could impact the comparisons between the two cities' LCZs. Because the two cities are smaller than traditionally studied cities for LCZ research, there is going to be a lack of homogenous land use/land cover for each LCZ category over large areas. Since the land uses (especially in the more urban areas) can vary greatly street by street, it is assumed that there would be UHI spillover effects from the surrounding areas near the sample sites (Stewart and Oke 2012); that is, one waterbody site might be adjacent to dense forest, whereas another waterbody site might be adjacent to OLR development. For example, Rinner and Hussain (2011) noted in their research on 


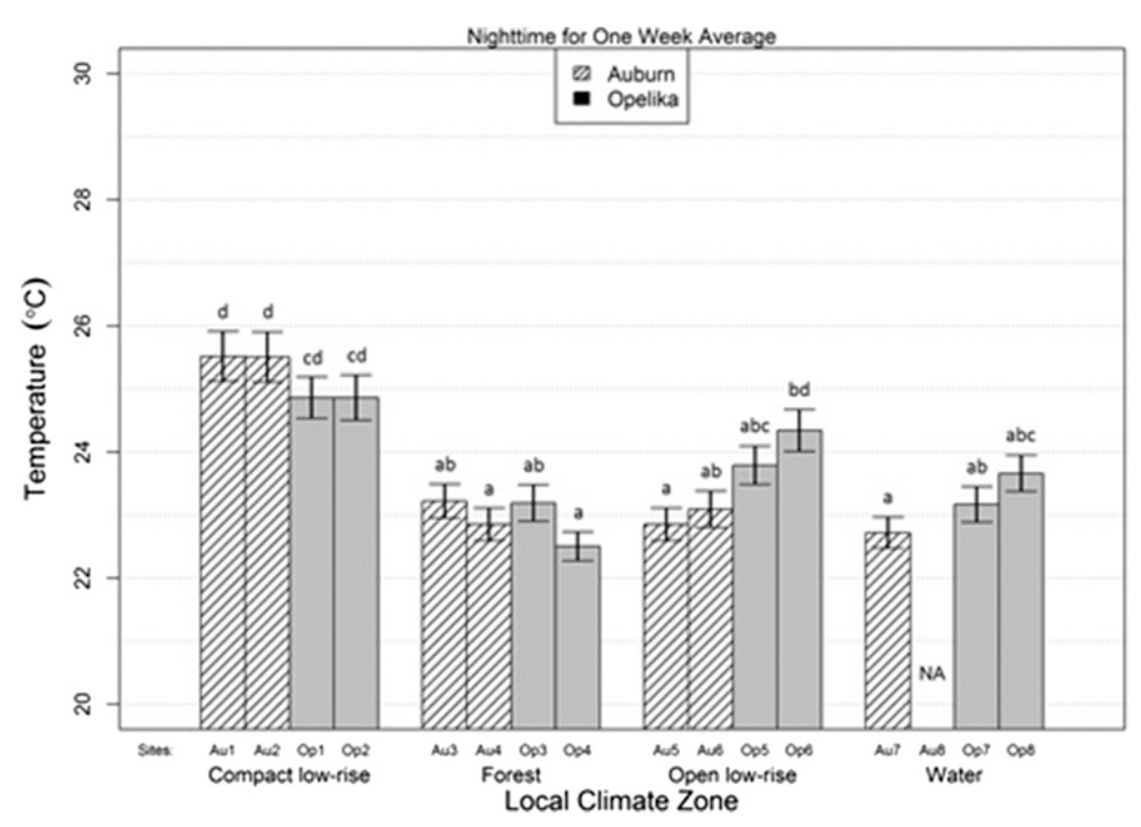

Figure 9. As in Figure 7, but during nighttime hours (1900-0500 LT).

the Toronto, Ontario, Canada, UHI that there were noticeable intraurban heat island effects that varied because of land uses. They demonstrated that the homogeneity of land uses exacerbates temperature extremes within the localized UHI effects. Since the respective sites in each city are smaller (in comparison with larger cities), it might be more challenging to directly compare the LCZs between the two cities since the LCZs are at a more microlevel of focus in these cities. This is why it might be beneficial to implement the use of a finer grid when creating the LCZs so that the results can be in a "matching resolution" of the cities (i.e., smaller city = smaller LCZs; therefore, a smaller grid is needed). Similarly, larger-city LCZs of the same type may behave very differently as a result of changes in surrounding features, such as elevation (Kaloustian and Bechtel 2016). Others have found wind to be a large determinant of intra-LCZ temperature variability (van Hove et al. 2015). Others have found different types of plant species in green space can affect

Table 2. Daily and whole-week UHI for CLR and OLR relative to forest LCZ for Opelika.

\begin{tabular}{lccccccc}
\hline & \multicolumn{3}{c}{ Compact low-rise } & & \multicolumn{3}{c}{ Open low-rise } \\
\cline { 2 - 4 } Date & Overall & Day & Night & & Overall & Day & Night \\
\hline 11 Jun 2015 & 1.7 & 2.0 & 1.2 & & 1.0 & 1.2 & 0.8 \\
12 Jun 2015 & 0.8 & 0.7 & 0.9 & & 0.4 & 0.4 & 0.5 \\
13 Jun 2015 & 1.9 & 2.3 & 1.4 & & 1.4 & 1.7 & 1.0 \\
14 Jun 2015 & 2.5 & 2.9 & 2.1 & & 1.9 & 2.1 & 1.6 \\
15 Jun 2015 & 2.9 & 2.8 & 3.1 & & 1.9 & 1.9 & 1.9 \\
16 Jun 2015 & 2.7 & 2.7 & 2.8 & & 1.7 & 1.7 & 1.6 \\
17 Jun 2015 & 2.5 & 2.5 & 2.6 & & 1.3 & 1.5 & 1.2 \\
Total & 2.2 & 2.3 & 2.0 & & 1.4 & 1.5 & 1.2 \\
\hline
\end{tabular}


Earth Interactions • Volume 22 (2018) • Paper No. 16 • Page 16

Table 3. As in Table 2, but for Auburn.

\begin{tabular}{lcccrrrr}
\hline & \multicolumn{3}{c}{ Compact low-rise } & & \multicolumn{3}{c}{ Open low-rise } \\
\cline { 2 - 3 } Date & Overall & Day & Night & & Overall & Day & Night \\
\hline 11 Jun 2015 & 1.7 & 2.0 & 1.4 & & 0.0 & 0.2 & -0.2 \\
12 Jun 2015 & 0.6 & 0.8 & 0.5 & & -0.3 & -0.3 & -0.3 \\
13 Jun 2015 & 2.1 & 2.6 & 1.5 & 0.4 & 0.7 & 0.0 \\
14 Jun 2015 & 3.0 & 3.3 & 2.6 & 0.6 & 0.9 & 0.2 \\
15 Jun 2015 & 3.8 & 3.7 & 4.0 & & 0.5 & 0.8 & 0.0 \\
16 Jun 2015 & 3.6 & 3.5 & 3.8 & & 0.5 & 0.8 & 0.0 \\
17 Jun 2015 & 3.5 & 3.5 & 3.6 & & 0.3 & 0.6 & -0.1 \\
Total & 2.6 & 2.8 & 2.5 & & 0.3 & 0.5 & -0.1 \\
\hline
\end{tabular}

overall UHI intensity (Feyisa et al. 2014). Therefore, the issue of spillover should be examined in the future when using LCZs and other types of land-cover characteristics. In our case, we were unable to generate site-specific wind speed/ direction data that could affect spillover; however, regional weather conditions (see section 3.1) were unable to explain much of our results (e.g., strong westerly wind with sites arranged from west to east). While problematic, the cause and result of spillover may be a key topic in understanding how UHIs develop and can be mitigated (Rizwan et al. 2008; Oliveira et al. 2011; Feyisa et al. 2014; Santamouris 2014).

\subsection{Detecting UHI intensity using LCZs}

Although challenging, the use of LCZs to detect UHI intensity was successful in both Auburn and Opelika with varying degrees. In both cities, the more-urban LCZs (compact low-rise and open low-rise) did have greater daytime, nighttime, and overall temperatures than surrounding forests. We hypothesized that the LCZ classification system could be used to detect UHI and that urban intensity would increase temperature overall, during the day, and at night. The daytime UHI intensity appeared most sensitive to nighttime and overall temperatures (Tables 2 and 3). While values for Auburn and Opelika CLR sites were comparable, OLR sites were distinct between cities. This result indicates that LCZs do not indicate UHI intensity similarly across LCZs, and we therefore reject that hypothesis.

Water sites represent another unique challenge in detecting UHI. Among the three water sites, variability in temperatures was specific to daytime, nighttime, and overall temperatures. Whole-day and daytime temperatures were significantly lower at the Auburn water site relative to Opelika water sites (Figures 7 and 8). During nighttime (Figure 9), temperatures were comparable. In contrast with other $\mathrm{LCZs,}$, temperatures at water sites were comparable to forests, except during daytime, when they were greater (and more comparable to CLR and OLR sites). We did not quantify water temperatures; however, sunlight penetration, waterbody size, and water base (sand, concrete, soil, etc.) could have important influences on surface temperatures.

For this study, we did not monitor traffic patterns, which could indicate a difference between cities since Auburn has a population almost double that of Opelika. $\mathrm{Ng}$ (2015) found that these anthropogenic activities did influence the UHI and 
Earth Interactions - Volume 22 (2018) • Paper No. 16 • Page 17

likely warrant further investigation in Auburn and Opelika. Auburn is home to Auburn University and to $\sim 25000$ students who are not necessarily present yearround, particularly in the warmer months (summer break). The university area is directly adjacent to both Auburn CLR sites. The contribution of commuting vehicles during multiple seasons should warrant further investigation, particularly in the context of air quality. The region is already rich in volatile organic compounds, both from anthropogenic emissions and vegetation (Ayres et al. 2015), and automobiles can also contribute to nitrogen oxides, leading to the formation of tropospheric ozone (Gonzalez-Abraham et al. 2015). Stathopoulou et al. (2008) found that increased temperatures associated with UHI were contributing to increased ozone concentrations in Athens, Georgia (another city along the I-85 corridor). The increased power demands associated with UHIs (cooling and electricity costs, social habit shifts in driving rather than walking) are also responsible for decreased air quality via increased fossil fuel combustion (Nemet et al. 2010; Harlan and Ruddell 2011).

The lack of UHI presence at Auburn's OLR sites relative to the forest sites was surprising, because others have found a potential UHI of $25 \%-50 \%$ in these zones (Middel et al. 2014). This was likely due to the distribution of sites selected. The CLR section of Auburn is large, is centered near Auburn University, and tends to become rural very quickly. In Opelika, where the two urban LCZs were more comparable in location (i.e., distance between sites and LCZs), sites were congregated near the central business district (Fig. 5). This presents another example in which LCZs may not be suitable for use in smaller cities.

\subsection{Comparable UHIs}

We hypothesized that the UHI effect would be similar in both Auburn and Opelika, suggesting that LCZs could be used in similarly sized cities to predict potential UHI intensities. In both Auburn and Opelika, CLR sites nearly always had a greater UHI than the OLR sites, indicating that the more urban spaces did have the greatest temperature increase. Over the course of the week, mean UHI intensity at CLR sites was $2.6^{\circ}$ and $2.2^{\circ} \mathrm{C}$ for Auburn and Opelika, respectively. From the two LCZs, we reject the notion that the UHI effect would be similar in both Auburn and Opelika. This result may be due to the location of sites, similar to what occurred for the first hypothesis. In addition to site distribution, local "urban form" plays a large role in local temperature anomalies. Stewart et al. (2014), when comparing three cities, found that building height/spacing, soil wetness and characteristics, and vegetation density largely mediate temperature contrasts between LCZs. Here, we provide evidence that thermal contrasts within LCZs are also likely to occur. This makes sense, as the total structure of sites (within the same LCZs, i.e., replicates) is slightly different, and their adjacent LCZs (and background climates) may vary. As a result, the GIS-based approach should be used with caution when using data for larger analyses.

The lack of UHI in OLR sites in Auburn is likely a result of the intra-LCZ variation in temperature (supplemental Figure S3). Temperature at site Au5 noticeably lagged during warming periods and subsequently never reached comparable maximum temperatures to the remaining OLR sites, which were all similar. Site Op6 tended to have a greater maximum temperature than other OLR sites; 
Earth Interactions - Volume 22 (2018) • Paper No. 16 • Page 18

however, there was continued warming for $\sim 1 \mathrm{~h}$ after other sites had reached their maxima. As a result, Auburn UHI for OLR tended to be less than that of Opelika. The cause for intra-LCZ temperature variation at Au5 is less explicable than that at Op6. Site Op6 tends to be closer to the CLR sites than the other Opelika OLR site. At Auburn, Au5 was very similar in both ground-level characteristics to Au6 and was similar in distance to CLR sites, leaving a minimal possibility for temperature blending. Uniformity in temperature variation among CLR temperatures was high, with the exception of Op1 (see Figure S1 of the online supplemental material). Although Op1 had similar warming and cooling rates around the maximum temperature, the realized maximum was less than that at the remaining CLR sites. Both CLR sites in Opelika were close, which indicates that intra-LCZ temperature variation is a concern when using the LCZ system to detect potential UHIs.

\subsection{Notes on the LCZ classification system}

The development of LCZs by Stewart and Oke (2012) has been an incredibly useful tool to aid in understanding urban climatology and ecology. For utility in understanding UHI, we found that in smaller cities there are several limitations. The urban LCZs for our sites were difficult to assess in Auburn and Opelika. The importance of urban green spaces is very important for microclimate. Although green spaces are incorporated into the LCZ classification system, these can be very diverse and difficult to examine. For example, when establishing the study, we considered using municipal parks as rural areas. In this case we found it difficult because municipal parks can incorporate many LCZs in a small area. For example, one park at the west end of Auburn (Kiesel Park) incorporates open fields (LCZ D), several ponds ( $\mathrm{LCZ} \mathrm{G}$ ), a few buildings (a barn, a community center, and a few houses) (LCZ 9), and pine plantations (LCZ A) in a $1.25-\mathrm{km}^{2}$ area. Although Stewart and Oke (2012) address "subclasses," it becomes very difficult to define these diverse areas, hence their exclusion from our study. This challenge will likely become more difficult for those using the LCZ system in smaller cities, especially when considering that thermal climate at near ground level blends into neighboring zones (Stewart and Oke 2012).

Background climate of a region plays a large role in the UHI intensity (Zhao et al. 2014; $\mathrm{Ng} \mathrm{2015).} \mathrm{In} \mathrm{mesic} \mathrm{regions,} \mathrm{the} \mathrm{role} \mathrm{of} \mathrm{water} \mathrm{may} \mathrm{play} \mathrm{a} \mathrm{large} \mathrm{role} \mathrm{in}$ UHI intensity (Steeneveld et al. 2014). We saw a great amount of variability across water sites. This is likely due to the volume of water and amount of sunlight experienced at each site (e.g., vapor pressure deficit). We utilized bodies of water that were generally removed from urban zones; however, future studies should investigate the ability of bodies of water to buffer/contribute to UHI. Similar to water zones, forests are another challenge for using the LCZ system. The classifications of "dense trees" and "scattered trees" may not always be sufficient (Middel et al. 2014). In the rural areas surrounding Auburn and Opelika, we were fortunate to select four sites that were plantations of a single species (Pinus taeda L.) with similar structures. In smaller cities, we expect others will find it challenging to select appropriate sites using the coarse categories; however, we acknowledge this was not the ultimate goal of the LCZ system. We would recommend, in the future, to blend the use of LCZs with the method of Middel et al. (2014), where sites were 
Earth Interactions - Volume 22 (2018) • Paper No. 16 • Page 19

chosen as xeric, mesic, and oasis to provide direct contrasts with respect to urban form. The inherent diversity of features within each LCZ can make this difficult without choosing a specific set of characteristics in urban form to compare. We suggest the use of LCZs in smaller cities for urban planning and climate studies, but, when possible, more consideration should be given to contrasting urban forms or defining specific intra-LCZ differences. The diurnal role of UHIs is also difficult because different LCZs can warm or cool at unique rates.

\section{Conclusions}

Overall, we found the use and methodology of the LCZ system to be straightforward but recognized several limitations. Nonetheless, we were able to utilize the LCZ system to address our hypothesis regarding urban climate in a rapidly urbanizing region. With respect to our hypothesis, we accept that the LCZ system can be used to find areas that have the potential to see elevated temperatures associated with UHIs. Although we were able to detect UHIs, we reject the hypothesis that LCZs would have the same UHI intensity in multiple cities. This was most likely a result of site distribution in each city and differences between forms within LCZs. In addition, we acknowledge that many factors contribute to the presence and intensity of UHIs, not all of which were not considered in our 1-week observational study.

Acknowledgments. The authors thank the reviewers for their comments and suggestions, which greatly improved the quality of the paper. Seval Celik assisted with datalogger box assembly. Kathryn Fuller assisted in creating the I-85 corridor map.

\section{References}

Alexander, P. J., and G. Mills, 2014: Local climate classification and Dublin's urban heat island. Atmosphere, 5, 755-774, https://doi.org/10.3390/atmos5040755.

Ayres, B. R., and Coauthors, 2015: Organic nitrate aerosol formation via $\mathrm{NO}_{3}+$ biogenic volatile organic compounds in the southeastern United States. Atmos. Chem. Phys., 15, 1337713 392, https://doi.org/10.5194/acp-15-13377-2015.

Balchin, W. G. V., and N. Pye, 1947: A micro-climatological investigation of Bath and the surrounding district. Quart. J. Roy. Meteor. Soc., 73, 297-323, https://doi.org/10.1002/ qj.49707331706.

Bernhard, M. C., S. T. Kent, M. E. Sloan, M. B. Evans, L. A. McClure, and J. M. Gohlke, 2015: Measuring personal heat exposure in an urban and rural environment. Environ. Res., 137, 410-418, https://doi.org/10.1016/j.envres.2014.11.002.

Bornstein, R. D., 1968: Observations of the urban heat island effect in New York City. J. Appl. Meteor., 7, 575-582, https://doi.org/10.1175/1520-0450(1968)007<0575:OOTUHI>2.0.CO;2.

—_, and Q. Lin, 2000: Urban heat islands and summertime convective thunderstorms in Atlanta: Three case studies. Atmos. Environ., 34, 507-516, https://doi.org/10.1016/ S1352-2310(99)00374-X.

Box, G. E. P., 1953: Non-normality and tests on variances. Biometrika, 40, 318-335, https://doi.org/ $10.2307 / 2333350$.

Chang, C.-R., M.-H. Li, and S.-D. Chang, 2007: A preliminary study on the local cool-island intensity of Taipei city parks. Landscape Urban Plan., 80, 386-395, https://doi.org/10.1016/ j.landurbplan.2006.09.005. 


\section{Earth Interactions - Volume 22 (2018) - Paper No. 16 • Page 20}

Chow, W. T. L., and M. Roth, 2006: Temporal dynamics of the urban heat island of Singapore. Int. J. Climatol., 26, 2243-2260, https://doi.org/10.1002/joc.1364.

Cohen, B., 2006: Urbanization in developing countries: Current trends, future projections, and key challenges for sustainability. Technol. Soc., 28, 63-80, https://doi.org/10.1016/ j.techsoc.2005.10.005.

Cui, Y. Y., and B. de Foy, 2012: Seasonal variations of the urban heat island at the surface and the near-surface and reductions due to urban vegetation in Mexico City. J. Appl. Meteor. Climatol., 51, 855-868, https://doi.org/10.1175/JAMC-D-11-0104.1.

Dou, J., Y. Wang, R. Bornstein, and S. Miao, 2015: Observed spatial characteristics of Beijing urban climate impacts on summer thunderstorms. J. Appl. Meteor. Climatol., 54, 94-105, https:// doi.org/10.1175/JAMC-D-13-0355.1.

Feyisa, G. L., K. Dons, and H. Meilby, 2014: Efficiency of parks in mitigating urban heat island effect: An example from Addis Ababa. Landscape Urban Plan., 123, 87-95, https://doi.org/ 10.1016/j.landurbplan.2013.12.008.

Frumkin, H., 2002: Urban sprawl and public health. Public Health Rep., 117, 201-217, https:// doi.org/10.1016/S0033-3549(04)50155-3.

Gonzalez-Abraham, R., and Coauthors, 2015: The effects of global change upon United States air quality. Atmos. Chem. Phys., 15, 12 645-12 665, https://doi.org/10.5194/acp-15-12645-2015.

Grimmond, S., 2007: Urbanization and global environmental change: Local effects of urban warming. Geogr. J., 173, 83-88, https://doi.org/10.1111/j.1475-4959.2007.232_3.x.

Harlan, S. L., and D. M. Ruddell, 2011: Climate change and health in cities: Impacts of heat and air pollution and potential co-benefits from mitigation and adaptation. Curr. Opin. Environ. Sustain., 3, 126-134, https://doi.org/10.1016/j.cosust.2011.01.001.

Hayhoe, K., and Coauthors, 2004: Emissions pathways, climate change, and impacts on California. Proc. Natl. Acad. Sci. USA, 101, 12422-12 427, https://doi.org/10.1073/ pnas.0404500101.

Heilig, G. K., 2012: World urbanization prospects: The 2011 revision. United Nations Department of Economic and Social Affairs Rep., 318 pp., http://www.un.org/en/development/desa/ population/publications/pdf/urbanization/WUP2011_Report.pdf.

Huband, N. D. S., S. C. King, M. W. Huxley, and D. R. Butler, 1984: The performance of a thermometer screen on an automatic weather station. Agric. For. Meteor., 33, 249-258, https://doi.org/10.1016/0168-1923(84)90074-1.

Hug, A. W., 2014: The study of urban heat islands in the Birmingham and Auburn-Opelika, Alabama urban areas, using satellite and observational techniques. M.S. thesis, Dept. of Geography, Auburn University, 162 pp., http://etd.auburn.edu/handle/10415/4446.

Imhoff, M. L., P. Zhang, R. E. Wolfe, and L. Bounoua, 2010: Remote sensing of the urban heat island effect across biomes in the continental USA. Remote Sens. Environ., 114, 504-513, https://doi.org/10.1016/j.rse.2009.10.008.

Kaloustian, N., and B. Bechtel, 2016: Local climatic zoning and urban heat island in Beirut. Procedia Eng., 169, 216-223, https://doi.org/10.1016/j.proeng.2016.10.026.

Leconte, F., J. Bouyer, R. Claverie, and M. Pétrissans, 2015: Using local climate zone scheme for UHI assessment: Evaluation of the method using mobile measurements. Build. Environ., 83, 39-49, https://doi.org/10.1016/j.buildenv.2014.05.005.

Li, D., E. Bou-Zeid, and M. Oppenheimer, 2014: The effectiveness of cool and green roofs as urban heat island mitigation strategies. Environ. Res. Lett., 9, 055002, https://doi.org/10.1088/ $1748-9326 / 9 / 5 / 055002$.

Lockaby, B. G., D. Zhang, J. McDaniel, H. Tian, and S. Pan, 2005: Interdisciplinary research at the urban-rural interface: The west GA project. Urban Ecosyst., 8, 7-21, https://doi.org/10.1007/ s11252-005-1416-3.

Lowry, W. P., and P. P. Lowry, 2001: Fundamentals of Biometeorology: The Physical Environment. Fundamentals of Biometeorology: Interactions of Organisms and the Atmosphere, Vol. 1. Peavine Publications/Missouri Botanical Garden Press, 650 pp. 


\section{Earth Interactions - Volume 22 (2018) • Paper No. 16 • Page 21}

Markowski, C. A., and E. P. Markowski, 1990: Conditions for the effectiveness of a preliminary test of variance. Amer. Stat., 44, 322-326, https://doi.org/10.2307/2684360.

McDonnell, M. J., S. T. A. Pickett, and R. V. Pouyat, 1993: The application of the ecological gradient paradigm to the study of urban effects. Humans as Components of Ecosystems, M. J. McDonnell and S. T. A. Pickett, Eds., Springer, 175-189, http://link.springer.com/chapter/ 10.1007/978-1-4612-0905-8_15.

_ , and Coauthors, 1997: Ecosystem processes along an urban-to-rural gradient. Urban Ecosyst., 1, 21-36, https://doi.org/10.1023/A:1014359024275.

McMichael, A. J., 2000: The urban environment and health in a world of increasing globalization: Issues for developing countries. Bull. World Health Organ., 78, 1117-1126.

Middel, A., K. Häb, A. J. Brazel, C. A. Martin, and S. Guhathakurta, 2014: Impact of urban form and design on mid-afternoon microclimate in Phoenix local climate zones. Landscape Urban Plan., 122, 16-28, https://doi.org/10.1016/j.landurbplan.2013.11.004.

Mills, G., B. Bechtel, J. Ching, L. See, J. Feddema, M. Foley, P. Alexander, and M. O'Connor, 2015: An introduction to the WUDAPT project. Proc. Ninth Int. Conf. on Urban Climate, Toulouse, France, Météo France, 20-24.

Mitra, C., J. M. Shepherd, and T. Jordan, 2012: On the relationship between the premonsoonal rainfall climatology and urban land cover dynamics in Kolkata City, India. Int. J. Climatol., 32, 1443-1454, https://doi.org/10.1002/joc.2366.

Morris, C. J. G., I. Simmonds, and N. Plummer, 2001: Quantification of the influences of wind and cloud on the nocturnal urban heat island of a large city. J. Appl. Meteor., 40, 169-182, https:// doi.org/10.1175/1520-0450(2001)040<0169:QOTIOW > 2.0.CO;2.

Nagy, R. C., and B. G. Lockaby, 2011: Urbanization in the southeastern United States: Socioeconomic forces and ecological responses along an urban-rural gradient. Urban Ecosyst., 14, 71-86, https://doi.org/10.1007/s11252-010-0143-6.

Nemet, G. F., T. Holloway, and P. Meier, 2010: Implications of incorporating air-quality co-benefits into climate change policymaking. Environ. Res. Lett., 5, 014007, https://doi.org/10.1088/ $1748-9326 / 5 / 1 / 014007$.

Ng, Y. X. Y., 2015: A study of urban heat island using "local climate zones"- The case of Singapore. Brit. J. Environ. Climate Change, 5, 116-133, https://doi.org/10.9734/BJECC/2015/13051.

Noe, R. S., J. O. Jin, and A. F. Wolkin, 2012: Exposure to natural cold and heat: Hypothermia and hyperthermia Medicare claims, United States, 2004-2005. Amer. J. Public Health, 102, e11-e18, https://doi.org/10.2105/AJPH.2011.300557.

Oke, T. R., 1982: The energetic basis of the urban heat island. Quart. J. Roy. Meteor. Soc., 108, 1-24, https://doi.org/10.1002/qj.49710845502.

Oliveira, S., H. Andrade, and T. Vaz, 2011: The cooling effect of green spaces as a contribution to the mitigation of urban heat: A case study in Lisbon. Build. Environ., 46, 2186-2194, https:// doi.org/10.1016/j.buildenv.2011.04.034.

Peng, R. D., J. F. Bobb, C. Tebaldi, L. McDaniel, M. L. Bell, and F. Dominici, 2011: Toward a quantitative estimate of future heat wave mortality under global climate change. Environ. Health Perspect., 119, 701-706, https://doi.org/10.1289/ehp.1002430.

Rahman, M., 2014: Growth of Alabama urban areas and its impact on changing environmental dynamics. M.S. thesis, Dept. of Geography, Auburn University, 108 pp., http://etd.auburn.edu/ handle/10415/4267.

Rinner, C., and M. Hussain, 2011: Toronto's urban heat island-Exploring the relationship between land use and surface temperature. Remote Sens., 3, 1251-1265, https://doi.org/10.3390/rs3061251.

Rizwan, A. M., L. Y. C. Dennis, and C. Liu, 2008: A review on the generation, determination and mitigation of urban heat island. J. Environ. Sci., 20, 120-128, https://doi.org/10.1016/ S1001-0742(08)60019-4.

Santamouris, M., 2014: Cooling the cities-A review of reflective and green roof mitigation technologies to fight heat island and improve comfort in urban environments. Sol. Energy, 103, 682-703, https://doi.org/10.1016/j.solener.2012.07.003. 
Earth Interactions - Volume 22 (2018) - Paper No. 16 • Page 22

Savić, S., D. Milošević, L. Lazić, V. Marković, D. Arsenović, and D. Pavić, 2013: Classifying urban meteorological stations sites by "local climate zones": Preliminary results for the city of Novi Sad (Serbia). Geographica Pannonica, 17, 60-68, https://doi.org/10.5937/ GeoPan1303060S.

Sheridan, S. C., C. C. Lee, M. J. Allen, and L. S. Kalkstein, 2012: Future heat vulnerability in California. Part I: Projecting future weather types and heat events. Climatic Change, 115, 291-309, https://doi.org/10.1007/s10584-012-0436-2.

Sparks, W. R., 1972: The effect of thermometer screen design on the observed temperature. WMO Rep. 315, 114 pp., https://library.wmo.int/pmb_ged/wmo_315_en.pdf.

Stathopoulou, E., G. Mihalakakou, M. Santamouris, and H. S. Bagiorgas, 2008: On the impact of temperature on tropospheric ozone concentration levels in urban environments. J. Earth Syst. Sci., 117, 227-236, https://doi.org/10.1007/s12040-008-0027-9.

Steeneveld, G. J., S. Koopmans, B. G. Heusinkveld, and N. E. Theeuwes, 2014: Refreshing the role of open water surfaces on mitigating the maximum urban heat island effect. Landscape Urban Plan., 121, 92-96, https://doi.org/10.1016/j.landurbplan.2013.09.001.

Stewart, I. D., 2011: A systematic review and scientific critique of methodology in modern urban heat island literature. Int. J. Climatol., 31, 200-217, https://doi.org/10.1002/joc.2141.

— - and T. R. Oke, 2012: Local climate zones for urban temperature studies. Bull. Amer. Meteor. Soc., 93, 1879-1900, https://doi.org/10.1175/BAMS-D-11-00019.1.

— - - and E. S. Krayenhoff, 2014: Evaluation of the "local climate zone" scheme using temperature observations and model simulations. Int. J. Climatol., 34, 1062-1080, https://doi.org/10.1002/joc.3746.

Stone, B., J. J. Hess, and H. Frumkin, 2010: Urban form and extreme heat events: Are sprawling cities more vulnerable to climate change than compact cities? Environ. Health Perspect., 118, 1425-1428, https://doi.org/10.1289/ehp.0901879.

van Hove, L. W. A., C. M. J. Jacobs, B. G. Heusinkveld, J. A. Elbers, B. L. van Driel, and A. A. M. Holtslag, 2015: Temporal and spatial variability of urban heat island and thermal comfort within the Rotterdam agglomeration. Build. Environ., 83, 91-103, https://doi.org/10.1016/ j.buildenv.2014.08.029.

Voorhees, A. S., N. Fann, C. Fulcher, P. Dolwick, B. Hubbell, B. Bierwagen, and P. Morefield, 2011: Climate change-related temperature impacts on warm season heat mortality: A proof-ofconcept methodology using BenMAP. Environ. Sci. Technol., 45, 1450-1457, https://doi.org/ $10.1021 /$ es $102820 y$.

Wear, D. N., and J. G. Greis, 2002: Southern forest resource assessment-Technical report. U.S. Department of Agriculture Southern Research Station General Tech. Rep. (GTR)-SRS-053, 628 pp., http://www.srs.fs.usda.gov/pubs/viewpub.php?index $=4833$.

Zhao, L., X. Lee, R. B. Smith, and K. Oleson, 2014: Strong contributions of local background climate to urban heat islands. Nature, 511, 216-219, https://doi.org/10.1038/nature13462.

Earth Interactions is published jointly by the American Meteorological Society, the American Geophysical Union, and the Association of American Geographers. For information regarding reuse of this content and general copyright information, consult the AMS Copyright Policy (www.ametsoc.org/PUBSReuseLicenses). 